\title{
One out of three bystanders of out-of-hospital cardiac arrests suffers pathological psychological processing a few weeks after the incident- results from a systematic telephone interview
}

\section{Peter Brinkrolf}

Department of Anaesthesiology

Bibiana Metelmann ( $\sim$ bibiana.metelmann@uni-greifswald.de )

University Medicine Greifswald https://orcid.org/0000-0003-2090-7358

Camilla Metelmann

Department of Anaesthesiology

Mina Baumgarten

Universitaetsmedizin Greifswald

Carolin Scharte

Department of Anaesthesiology

Alexander Zarbock

Department of Anaesthesiology

Klaus Hahnenkamp

Department of Anaesthesiology

Andreas Bohn

City of Muenster Fire Department

Original research

Keywords: Bystander CPR, Ethics, Out-of-hospital CPR, out-of-hospital cardiac arrest, Witnessed cardiac arrest, Psychological Distress, Emotional Adjustment, Psychological Trauma

Posted Date: November 2nd, 2020

DOl: https://doi.org/10.21203/rs.3.rs-98927/v1

License: (9) (1) This work is licensed under a Creative Commons Attribution 4.0 International License. Read Full License 


\section{Abstract}

\section{Background}

Witnessing an out-of-hospital cardiac arrest (OHCA) is a traumatic experience. It is known, that some bystanders struggle with coping of these events. The impact of (part-) performing CPR vs. passive observing OHCA and of being a stranger as bystander vs. family and friends of the patient is still unknown.

Methods

Between December 2014 and April 2016 bystanders, who witnessed an OHCA of an adult patient (>18 years) were interviewed by telephone a few weeks after the event. In a semi-standardized questionnaire the paramount emotion at the time of the interview was asked. The statements given in response to open questions were rated into the categories "signs of pathological psychological processing", "physiological psychological processing" and "good mental constitution" by independent researchers.

Results

Observing the exclusion criteria 89 telephone interviews could be included in the analyses. In 27 out of 89 cases $(30.3 \%)$ signs of pathological psychological processing could be detected. Signs of pathological psychological processing were significantly less in bystanders, who received instructions by the dispatcher or autonomously performed CPR. No statistical significant differences in the psychological processing could be shown for gender, age, relationship to the patient, current employment in the health sector, location of cardiac arrest or number of additional bystanders.

Conclusions

One out of three bystanders of OHCA suffers sings of pathological psychological processing. This was independent of age, gender and relationship of the bystander to the patient. Bystanders who performed CPR with or without receiving instructions had a lower risk.

\section{Background}

Out-of-hospital cardiac arrest (OHCA) occurs in Europe with an incidence of 37-55 per 100,000 per year (Gräsner et al. 2014).

In (nearly) all cases of OHCA the emergency service is contacted by a bystander in the patient's surrounding. In around 50\% of OHCA the collapse is witnessed (Wissenberg et al. 2013). Episodic evidence indicates, that witnessing a cardiac arrest is perceived as a formative moment for most bystanders. It is known, that grief is a risk factor for physical and mental ill health (Parkes 2002). The suddenness of most OHCA, especially when leading to unexpected death and subsequent grief among the patient's family and friends, is a traumatic experience (Dubin and Sarnoff 1986; Wells 1993). Global 
academic research focussing on survivors of cardiac arrest has shown a high probability of developing posttraumatic stress disorder in this patient group (Spindler and Pedersen 2005; Gamper et al. 2004).

However, the impact of OHCA on bystanders is less known. A case study of paramedics in the city of Oslo noticed that the majority of paramedics (24 out of the 33 interviewed) reported attempts to care for grieving relatives after an unsuccessful resuscitation and described encountering significant difficulties (Steen et al. 1997). A number of articles controversially discussed whether being present during emergency team-led cardiopulmonary resuscitation (CPR) as a relative increases or decreases the risk for post-traumatic stress disorder (Stefano et al. 2016; Compton et al. 2009; Jabre et al. 2013). Mathiesen and colleagues interviewed 20 bystanders, who performed CPR, on how they processed this event and found that some struggled in life (feelings of guilt, reduced work capacity, weight loss, flashbacks and nightmares) even after years (Mathiesen et al. 2016). However, the previous research neither systematically evaluates the variable of strangers as bystanders vs. family and friends of the patient nor the impact of performing CPR (compression-only-CPR or compression and ventilation) vs. passive observing OHCA.

As part of a larger study of bystanders' perceptions of OHCA already published in extract in Resuscitation (Brinkrolf et al. 2018), we included a follow-up interview of bystanders of OHCA a few weeks after the incident examining key thoughts, memories, and emotions.

\section{Methods}

This analysis aims to describe the emotional state of bystanders of an OHCA a few weeks after the incident. The data presented are part of a larger data-set focussing on bystanders' perceptions after witnessing cardiac arrest.

Between December 2014 and April 2016 bystanders, who witnessed an OHCA of an adult patient (> 18 years) receiving CPR in the city of Münster (Germany), were included in the interview study. All bystanders were asked to take part in a telephone interview one to seven weeks after the event. Participants were recruited by the emergency physician on duty, who ascertained the first bystander at the scene obtaining verbal consent for passing on contact data to the researchers.

Cases of OHCA were excluded, if no bystander could be traced or if the cardiac arrest occurred in the presence of the ambulance team. Secondary exclusion criteria resulted from missing or incomplete contact data of the bystander, lack of bystanders' consent or failure to reach the bystander via phone for the interview.

The telephone interview followed a semi-standardized questionnaire consisting of 116 items and encompassed a spectrum of different topics such as the location of the incidence, the relationship between bystander and patient and individual characteristics of the bystander such as gender, age, highest qualification/degree, as well as the paramount emotion at the time of the interview. Every item 
was explored with a primary open question, followed by secondary specific question to secure full evaluation. Responses were documented verbatim.

Outcome of the CPR (survival vs. death) remained unknown to the researchers to eliminate emotional priming in the interpretation of the answers.

To minimize variation, a single researcher conducted all telephone interviews (Author: CS). The statements of the open question of the paramount emotion at the time of the interview were independently grouped across the entire participant cohort by two researchers - an emergency physician and a specialist psychiatrist (Author: $\mathrm{BM}$ and $\mathrm{MB}$ ). All cases of diverging classification of responses were discussed together with two further researchers (Author: CM and PB).

This article focuses on the quantitative analysis of different factors, which might influence the thoughts and emotions of bystanders at the time of interview.

Chi-square test was used to assess significance levels and Pearson's Chi-square test and phi coefficient to compare telephone-CPR and bystander-CPR. A p value $<0.05$ was rated significant. Statistical processing of the data was performed using Microsoft Excel 2010 (Microsoft Corporation, Redmond, Washington, USA) and IBM SPSS Statistics, version 24.0 (IBM Corporation, Armonk, New York, USA).

\section{Results}

\section{Demographics of participant cohort}

During the study period 310 OHCA were recorded in the German Resuscitation Registry as having occurred in the city of Münster. A total of 66 cases were excluded: 10 cases occurred inside a medical facility, in 5 cases the patient was under 18 years, in 18 cases resuscitation was neither attempted by bystander nor emergency team (e.g. palliative scenario), in 20 cases the ambulance team had been present when the OHCA occurred, in 13 cases no bystander was present. Out of the remaining 244 possible telephone interviews 101 (41.4\%) could be conducted. In 10 cases the interview was conducted within a week from the incident. We decided to exclude these cases from the analysis to diminish a bias by acute stress reaction. In 2 cases the question of the paramount emotion at the time of the interview was not answered. Therefore, we excluded these cases (Fig. 1).

[Figure 1 should appear here.]

A total of 54 women and 35 men were interviewed and included in the analysis. 58 bystanders performed CPR, while 31 did not. The median age of the bystanders was 54 years. The median time between cardiac arrest and interview was 18 days (minimum 7 days, maximum 47 days). In 54 cases the bystanders were relatives (35 spouses/ partners, 16 parents, 3 other relatives) of the OHCA patient, in 4 cases friends and in 6 cases colleagues. 25 bystanders did not know the cardiac arrest patient.

\section{Categories of psychological reaction}


The bystanders' main thoughts and principal emotion a few weeks after witnessing an OHCA were grouped into four categories: "signs of pathological psychological processing" (verbatim answers such as "flashbacks", "thin-skinned", "jumpy", "feeling of guilt"), "physiological psychological processing" (verbatim answers such as "affected", "very sad, but father was very ill"), "good mental constitution" (verbatim answers such as "content", "getting along"), and "not distinctly appraisable" (ambiguous phrasing), compare Additional file 1.

In 27 out of 89 cases signs of pathological psychological processing could be detected. In 19 out of the 89 cases the main feeling of the bystander could be qualified as a physiological psychological processing uncomplicated mourning reaction, while 37 bystanders reported good mental constitution without being affected by the experience. 6 cases were not distinctly appraisable (Table 1).

Table 1

Bystanders' principal emotion

\begin{tabular}{|ll|}
\hline Category & Number (total: 89) \\
\hline Signs of pathological psychological processing & 27 \\
\hline Physiological psychological processing & 19 \\
\hline Good mental constitution & 37 \\
\hline not distinctly appraisable & 6 \\
\hline
\end{tabular}

In $73(82.1 \%)$ cases the bystander's principal emotion were categorized the same by the two independent raters. In 16 cases $(17.9 \%)$ the principal emotion was rated differently and the category was determined together with a third and fourth rater.

Table 2 documents the tabulation in individual characteristics, such as age, gender and relationship with patient (intrinsic factors) and circumstances of the event such as location, number of additional bystanders (extrinsic factors). 
Table 2

Bystanders' principal emotion grouped after different intrinsic and extrinsic factors

\section{Total Signs of pathological \\ Number \\ psychological processing \\ Physiological \\ psychological \\ processing (\%)}

83

27 (32.5\%)
Good mental constitution

(\%)

All bystanders $\quad 83$

Male

33

8 (24.2\%)

$6(18.2 \%)$

19 (57.6\%)

Female

50

19 (38\%)

$13(26 \%)$

18 (36\%)

Age $(p=0.2372)$

$<35$ years

12

$2(16.7 \%)$

$3(25 \%)$

7 (58.3\%)

35-64 years

52

18 (34.6\%)

9 (17.3\%)

25 (48.1\%)

$>64$ years

19

7 (36.85\%)

7 (36.85\%)

$5(26.3 \%)$

Professional or voluntary work in the health sector $(p=0.1183)$

$\begin{array}{lllll}\text { Yes } & 18 & 7(38.9 \%) & 1(5.6 \%) & 10(55.5 \%) \\ \text { No } & 62 & 19(30.7 \%) & 18(29 \%) & 25(40.3 \%)\end{array}$

Relationship between patient and bystander $(p=0.3369)$

\begin{tabular}{lcccc}
$\begin{array}{l}\text { Know each } \\
\text { other }\end{array}$ & 60 & $22(36.7 \%)$ & $14(23.3 \%)$ & $24(40 \%)$ \\
\hline $\begin{array}{l}\text { Don't know } \\
\text { each other }\end{array}$ & 23 & $5(21.75 \%)$ & $5(21.75 \%)$ & $13(56.5 \%)$ \\
\hline
\end{tabular}

Degree of family $(p=0.4812)$

$\begin{array}{lcccc}\begin{array}{l}\text { Spouse/ } \\ \text { partner }\end{array} & 31 & 10(32.25 \%) & 11(35.5 \%) & 10(32.25 \%) \\ \text { Parent } & 16 & 6(37.5 \%) & 3(18.7 \%) & 7(43.8 \%)\end{array}$

Location of cardiac arrest $(p=0.5059)$

$\begin{array}{lllll}\text { Private place } & 57 & 17(29.8 \%) & 15(26.3 \%) & 25(43.9 \%) \\ \text { Workplace or } & 26 & 10(38.5 \%) & 4(15.4 \%) & 12(46.1 \%)\end{array}$

Number of additional bystanders $(p=0.3657)$

\begin{tabular}{|lllll|}
\hline 0 & 35 & $14(40 \%)$ & $10(28.6 \%)$ & $11(31.4 \%)$ \\
\hline 1 & 18 & $5(27.8 \%)$ & $3(16.7 \%)$ & $10(55.5 \%)$ \\
\hline More than 1 & 30 & $8(26.7 \%)$ & $6(20 \%)$ & $16(53.3 \%)$ \\
\hline
\end{tabular}




\section{Total Signs of pathological \\ Number \\ psychological processing \\ Physiological \\ psychological \\ processing (\%)}

Good mental constitution

(\%)

Telephone-CPR by dispatcher $(p<0.05)$

$\begin{array}{lllll}\text { Yes } & 30 & 6(20 \%) & 11(36.7 \%) & 13(43.3 \%) \\ \text { No } & 52 & 21(40.4 \%) & 8(15.4 \%) & 23(44.2 \%)\end{array}$

Bystander performed CPR $(p<0.05)$

$\begin{array}{lllll}\text { Yes } & 53 & 14(26.4 \%) & 10(18.9 \%) & 29(54.7 \%) \\ \text { No } & 30 & 13(43.3 \%) & 9(30 \%) & 8(26.7 \%)\end{array}$

Witnessed a cardiac arrest before $(p=0.8931)$

$\begin{array}{lllll}\text { Yes } & 22 & 8(36.4 \%) & 5(22.7 \%) & 9(40.9 \%) \\ \text { No } & 61 & 19(31.1 \%) & 14(23 \%) & 28(45.9 \%)\end{array}$

Person was responsive at the beginning $(p=0.6503)$

$\begin{array}{lllll}\text { Yes } & 17 & 6(35.3 \%) & 5(29.4 \%) & 6(35.3 \%) \\ \text { No } & 66 & 21(31.8 \%) & 14(21.2 \%) & 31(47 \%)\end{array}$

Initial breathing pattern $(p=0.6844)$

\begin{tabular}{lllll} 
No breathing & 36 & $10(27.8 \%)$ & $8(22.2 \%)$ & $18(50 \%)$ \\
$\begin{array}{l}\text { Agonal } \\
\text { breathing }\end{array}$ & 28 & $11(39.3 \%)$ & $6(21.4 \%)$ & $11(39.3 \%)$ \\
\hline
\end{tabular}

$\begin{array}{lllll}\begin{array}{l}\text { Breathing not } \\ \text { remembered }\end{array} & 14 & 4(28.6 \%) & 5(35.7 \%) & 5(35.7 \%)\end{array}$

Bystander was assured by something (e.g. bystanders, experiences) $(p=0.4621)$

$\begin{array}{lllll}\text { Yes } & 48 & 13(27.1 \%) & 12(25 \%) & 23(47.9 \%) \\ \text { No } & 35 & 14(40 \%) & 7(20 \%) & 14(40 \%)\end{array}$

First thought $(p=0.5445)$

\begin{tabular}{lcccc}
$\begin{array}{l}\text { I knew what to } \\
\text { do. }\end{array}$ & 37 & $14(37.8 \%)$ & $5(13.5 \%)$ & $18(48.7 \%)$ \\
$\begin{array}{l}\text { I didn't know } \\
\text { what to do. }\end{array}$ & 12 & $3(25 \%)$ & $4(33.3 \%)$ & $5(41.7 \%)$ \\
\hline $\begin{array}{l}\text { I was terrified. } \\
\begin{array}{l}\text { First thought } \\
\text { not } \\
\text { remembered }\end{array}\end{array}$ & 7 & $9(34.6 \%)$ & $7(26.9 \%)$ & $10(38.5 \%)$ \\
\hline
\end{tabular}


The six cases grouped as "not distinctly appraisable" were not included into the significance testing.

[Table 2 should appear here.]

In cases, where the dispatcher explained and instructed CPR, signs of pathological psychological processing were significantly less compared to cases without telephone-CPR $(20 \%$ vs. $40.4 \%, p<0.05)$, see Fig. 2.

[Figure 2 should appear here.]

The bystanders' rate of good mental health after witnessing OHCA was significantly higher in the group of bystanders performing CPR compared to those not resuscitating ( $54.7 \%$ vs. $26.7 \%, p<0.05)$, see Fig. 3 .

[Figure 3 should appear here.]

There were no significant differences in the psychological processing depending on intrinsic factors like gender, age, relationship to the patient and work in the health sector or extrinsic factors like location of cardiac arrest and number of additional bystanders.

Pearson's Chi-square test showed a significant correlation of medium strength between telephone-CPR by dispatcher and bystander performed $\operatorname{CPR}(\varphi=0.28 ; p=.008)$. In two cases it could not be determined, whether the dispatcher guided CPR, those were not included in the analysis.

\section{Discussion}

This work adds to the large body of evidence showing the impact of intrinsic and extrinsic factors on individuals' reaction to life events. The article focuses on the emotions and thoughts of bystanders, witnessing an OHCA by chance, a few weeks after the event.

While a high number of bystanders report good mental constitution after the event, around one third shows signs of pathological psychological processing including re-experiencing the event through intrusive recollections and flashbacks, increased arousal, anxiety and severe and recurring feelings of guilt.

Previous studies showed, that families of patients with acute syndromes (e.g. myocardial infarction) showed psychological distress (Bedsworth and Molen 1982; Dhooper 1990; Stewart et al. 2000; Weslien et al. 2005). Alarmingly, our analysis shows this might also be true for strangers. More than every fifth bystander, who witnesses the cardiac arrest of a stranger, shows signs of pathological psychological processing. Even though the bystander does not know the person, he has problems coping with the processing of the experience. Because the person is neither a family member nor a friend, it does not fit into the culturally accepted pattern of grieving a bereavement.

Signs of pathological psychological processing might occur only a short time but might also continue over longer periods influencing the life of this person in multiple aspects. It is therefore important to 
understand, which persons show signs of pathological psychological processing and identify factors, which might enhance the risk.

Our findings show a significant lower rate of pathological psychological processing in cases, where the dispatcher explained telephone-CPR. One might argue that the advice by the dispatcher gives the bystanders a clear instruction what to do and might be therefore perceived as a sharing of the responsibility for the treatment. Additionally, it helps the bystander to feel some control of the situation. Perceived control of a situation is associated with lower distress level and less posttraumatic stress disorder symptoms (Frazier et al. 2001; Frazier et al. 2011). This might reassure the bystander and therefore help him to process this experience. However, in contrast to that, in regard to the general question, whether the bystander was assured by something, there was just a trend towards fewer signs of pathological psychological processing that did not reach significance.

The parameters "dispatcher explained telephone-CPR" and "bystander performing CPR" are correlated with each other. Concordantly, a significant lower rate of pathological psychological processing occurred in cases where the bystander performed CPR. This is in line with available evidence on the protective impact of (perceived) self-efficacy when coping with significant stress (Meischke et al. 2011). Performing resuscitation is a laborious work, which leads to severe exhaustion of the bystander. In addition this might help the bystander to remember, that he did everything he could do to save the person from cardiac arrest.

Interestingly, although there is a trend towards more signs of pathological psychological processing among women than men, it did not reach significance. Likewise, there was no significant difference in signs of pathological psychological processing between the age groups of the bystander $<35$ years vs. $35-64$ years vs. $>65$ years.

Our analysis points to a number of considerations for the professionals involved in the management of OHCA.

1. To avoid the complications of pathological psychological processing in bystanders the authorities of emergency systems should plan, develop and implement measures to support bystanders through information on available support and easy access to professional assessment and help where needed. Exemplarily, Mausz and Tavares contacted 15 bystanders of cardiac arrest two weeks after the incident and performed a structured interview (Mausz et al. 2018). The authors found, that the bystanders had difficulties to varying degrees to deal with the distressing images and noticed, that the participants appreciated the opportunity for a debriefing with a health care professional (Mausz et al. 2018). Based on this, they developed and described a structured debriefing pathway in their "Lay Responder Post-Arrest Support Model" (Snobelen et al. 2018). This could be a starting point to develop a support system, that applies to families of OHCA victims as well as to strangers, who witnessed an OHCA.

2. We see an important additional benefit of campaigns promoting bystander- cardiopulmonary resuscitation (Perkins et al. 2015; Abella et al. 2008; Kleinman et al. 2017). While bystander-CPR 
enhances the probability of surviving a cardiac arrest (Hasselqvist-Ax et al. 2015; Tanaka et al. 2017;

Fordyce 2017; Riddersholm et al. 2017), our analysis also indicated that it can reduce the risks of bystanders for mental distress in consequence of the event.

\section{Limitations}

The general transferability of this study to other regions is reduced by the single-centre-design.

The study protocol included a wide range of different aspects regarding bystanders of OHCA. Therefore, a systematic psychological testing of the bystanders was not undertaken. The individual answers of the OHCA witnesses were later grouped into four categories. Although this process was done by four authors, the grouping could lead to a bias, because answers could be ambiguous or unclear. A translation of all answers is attached as Additional file 1.

We do not know, whether the patients survived the cardiac arrest. Therefore, we cannot determine the impact of survival on the feelings of the bystander. Then again, if the bystander was a stranger to the patient, details regarding survival of the patient will have remained unknown. No significant differences in the coping between bystanders who did or did not know the person were shown.

The response rate was $41.4 \%$, which might imply a considerable non-responder-bias. A total of 143 bystanders could not be interviewed. However, of those 93 bystanders could repeatedly not be reached. Only 31 bystanders actively refused to participate in the study.

\section{Conclusions}

This study provides insights into the emotional state of bystanders after witnessing a cardiac arrest. Our data give reason for concern, that one out of three bystanders of OHCA suffers sings of pathological psychological processing. The probability of such reactions was significantly lower in cases, where the dispatcher explained telephone-CPR and in cases, where the bystander started CPR. Our findings point to potential approaches for emergency authorities, including implementation of assessment of and support for bystanders, who witnessed cardiac arrest and campaigns promoting bystander-CPR. Further studies including a focused assessment of psychological and psychiatric signs and symptoms in bystanders are needed.

\section{Abbreviations}

OHCA

out-of-hospital cardiac arrest

CPR

cardiopulmonary resuscitation

\section{Declarations}




\section{- Ethics approval and consent to participate}

The approval of the ethics committee of the Medical Council of Westphalia-Lippe and the Medical Faculty of the University of Münster was obtained under case number 2013-329-f-S.

\section{- Consent for publication}

Not applicable

\section{- Availability of data and material}

The datasets used and analysed during the current study are available from the corresponding author on reasonable request.

\section{- Competing interests}

The authors declare that they have no competing interests.

\section{- Funding}

Not applicable

\section{- Authors' contributions}

$P B$ and $A B$ devised, initiated and supervised the study. $C S$ performed the telephone interviews. $B M, C M$, $\mathrm{MB}$ and $\mathrm{PB}$ analysed the data. MB provided psychiatric expertise to the interpretation of the data. $\mathrm{BM}, \mathrm{PB}$ and $M B$ wrote the manuscript. $A Z, K H$ and $A B$ oversaw the study and gave valuable input regarding design, analysis and interpretation of the data and improved the manuscript. All authors read and approved the final manuscript.

\section{- Acknowledgements}

Not applicable.

\section{References}

Abella BS, Aufderheide TP, Eigel B, Hickey RW, Longstreth WT, Nadkarni V, et al. Reducing barriers for implementation of bystander-initiated cardiopulmonary resuscitation: A scientific statement from the American Heart Association for healthcare providers, policymakers, and community leaders regarding the effectiveness of cardiopulmonary resuscitation. Circulation. 2008;117(5):704-9.

doi:10.1161/CIRCULATIONAHA.107.188486.

Bedsworth JA, Molen MT. Psychological stress in spouses of patients with myocardial infarction. Heart Lung. 1982;11(5):450-6. 
Brinkrolf P, Metelmann B, Scharte C, Zarbock A, Hahnenkamp K, Bohn A. Bystander-witnessed cardiac arrest is associated with reported agonal breathing and leads to less frequent bystander CPR.

Resuscitation. 2018;127:114-8. doi:10.1016/j.resuscitation.2018.04.017.

Compton S, Grace H, Madgy A, Swor RA. Post-traumatic stress disorder symptomology associated with witnessing unsuccessful out-of-hospital cardiopulmonary resuscitation. Acad Emerg Med. 2009;16(3):226-9. doi:10.1111/j.1553-2712.2008.00336.x.

Dhooper SS. Identifying and mobilizing social supports for the cardiac patient's family. J Cardiovasc Nurs. 1990;5(1):65-73.

Dubin WR, Sarnoff JR. Sudden unexpected death: Intervention with the survivors. Ann Emerg Med. 1986;15(1):54-7.

Fordyce CB. Reduced critical care utilization: Another victory for effective bystander interventions in cardiac arrest. Resuscitation. 2017;119:A4-A5. doi:10.1016/j.resuscitation.2017.08.009.

Frazier P, Berman M, Steward J. Perceived control and posttraumatic stress: A temporal model. Applied and Preventive Psychology. 2001;10(3):207-23. doi:10.1016/S0962-1849(01)80015-9.

Frazier P, Keenan N, Anders S, Perera S, Shallcross S, Hintz S. Perceived past, present, and future control and adjustment to stressful life events. J Pers Soc Psychol. 2011;100(4):749-65. doi:10.1037/a0022405.

Gamper G, Willeit M, Sterz F, Herkner H, Zoufaly A, Hornik K, et al. Life after death: Posttraumatic stress disorder in survivors of cardiac arrest-prevalence, associated factors, and the influence of sedation and analgesia. Crit Care Med. 2004;32(2):378-83. doi:10.1097/01.CCM.0000108880.97967.C0.

Gräsner J-T, Böttiger BW, Bossaert L. EuReCa ONE - ONE month - ONE Europe - ONE goal. Resuscitation. 2014;85(10):1307-8. doi:10.1016/j.resuscitation.2014.08.001.

Hasselqvist-Ax I, Riva G, Herlitz J, Rosenqvist M, Hollenberg J, Nordberg P, et al. Early cardiopulmonary resuscitation in out-of-hospital cardiac arrest. N Engl J Med. 2015;372(24):2307-15. doi:10.1056/NEJMoa1405796.

Jabre P, Belpomme V, Azoulay E, Jacob L, Bertrand L, Lapostolle F, et al. Family presence during cardiopulmonary resuscitation. N Engl J Med. 2013;368(11):1008-18. doi:10.1056/NEJMoa1203366.

Kleinman ME, Goldberger ZD, Rea T, Swor RA, Bobrow BJ, Brennan EE, et al. 2017 American Heart Association Focused Update on Adult Basic Life Support and Cardiopulmonary Resuscitation Quality: An Update to the American Heart Association Guidelines for Cardio pulmonary Resuscitation and Emergency Cardiovascular Care. Circulation 2017. doi:10.1161/CIR.0000000000000539.

Mathiesen WT, Bjørshol CA, Braut GS, Søreide E. Reactions and coping strategies in lay rescuers who have provided CPR to out-of-hospital cardiac arrest victims: A qualitative study. BMJ Open. 
2016;6(5):e010671. doi:10.1136/bmjopen-2015-010671.

Mausz J, Snobelen P, Tavares W. "Please. Don't. Die.": A Grounded Theory Study of Bystander Cardiopulmonary Resuscitation. Circ Cardiovasc Qual Outcomes. 2018;11(2):e004035. doi:10.1161/CIRCOUTCOMES.117.004035.

Meischke H, Diehr P, Phelps R, Damon S, Rea T. Psychologic effects of automated external defibrillator training: A randomized trial. Heart Lung. 2011;40(6):502-10. doi:10.1016/j.hrtlng.2010.12.009.

Parkes CM. Grief: Lessons from the past, visions for the future. Death Stud. 2002;26(5):367-85. doi:10.1080/07481180290087366.

Perkins GD, Handley AJ, Koster RW, Castrén M, Smyth MA, Olasveengen T, et al. European Resuscitation Council Guidelines for Resuscitation 2015: Section 2. Adult basic life support and automated external defibrillation. Resuscitation. 2015;95:81-99. doi:10.1016/j.resuscitation.2015.07.015.

Riddersholm S, Kragholm K, Mortensen RN, Pape M, Hansen CM, Lippert FK, et al. Association of bystander interventions and hospital length of stay and admission to intensive care unit in out-of-hospital cardiac arrest survivors. Resuscitation. 2017;119:99-106. doi:10.1016/j.resuscitation.2017.07.014.

Snobelen PJ, Pellegrino JL, Nevils GS, Dainty KN. Helping Those Who Help. Circ Cardiovasc Qual Outcomes. 2018;11(9):e004702. doi:10.1161/CIRCOUTCOMES.118.004702.

Spindler H, Pedersen SS. Posttraumatic stress disorder in the wake of heart disease: Prevalence, risk factors, and future research directions. Psychosom Med. 2005;67(5):715-23. doi:10.1097/01.psy.0000174995.96183.9b.

Steen E, Naess AC, Steen PA. Paramedics organizational culture and their care for relatives of cardiac arrest victims. Resuscitation. 1997;34(1):57-63.

Stefano C de, Normand D, Jabre P, Azoulay E, Kentish-Barnes N, Lapostolle F, et al. Family Presence during Resuscitation: A Qualitative Analysis from a National Multicenter Randomized Clinical Trial. PLoS One. 2016;11(6):e0156100. doi:10.1371/journal.pone.0156100.

Stewart M, Davidson K, Meade D, Hirth A, Makrides L. Myocardial infarction: Survivors' and spouses' stress, coping, and support. J Adv Nurs. 2000;31(6):1351-60.

Tanaka H, Ong MEH, Siddiqui FJ, Ma MHM, Kaneko H, Lee KW, et al. Modifiable Factors Associated With Survival After Out-of-Hospital Cardiac Arrest in the Pan-Asian Resuscitation Outcomes Study. Ann Emerg Med 2017. doi:10.1016/j.annemergmed.2017.07.484.

Wells PJ. Preparing for Sudden Death: Social Work in the Emergency Room. Social Work. 1993;38(3):339. 
Weslien M, Nilstun T, Lundqvist A, Fridlund B. When the unreal becomes real: family members' experiences of cardiac arrest. Nurs Crit Care. 2005;10(1):15-22. doi:10.1111/j.1362-1017.2005.00094.x.

Wissenberg M, Lippert FK, Folke F, Weeke P, Hansen CM, Christensen EF, et al. Association of national initiatives to improve cardiac arrest management with rates of bystander intervention and patient survival after out-of-hospital cardiac arrest. JAMA. 2013;310(13):1377-84. doi:10.1001/jama.2013.278483.

\section{Figures}


Cardiac arrest in the city of Münster

Primary excluded $(n=66)$ :

- Inside a medical facility $(\mathrm{n}=10)$

- Patient aged $<18$ years $(n=5)$

- No CPR attempted $(\mathrm{n}=18)$

- OHCA occurred in presence of emergency personnel $(\mathrm{n}=20)$

Possible telephone interviews $(\mathrm{n}=244)$

- Missing or incomplete contact data $(n=47)$

- Bystanders' non-approval to get contacted $(n=19)$

- No contact achieved to bystander $(n=46)$

- Refusal to take part $(\mathrm{n}=30)$

- Drop-out of telephone interview $(\mathrm{n}=1)$

Performed telephone interviews $(\mathrm{n}=101)$

Tertiary excluded $(n=12)$ :

- Interview conducted within a week of event $(n=10)$

- Question concerning paramount emotion not

Analysed cases $(\mathrm{n}=89)$

Figure 1

Included and excluded cases 


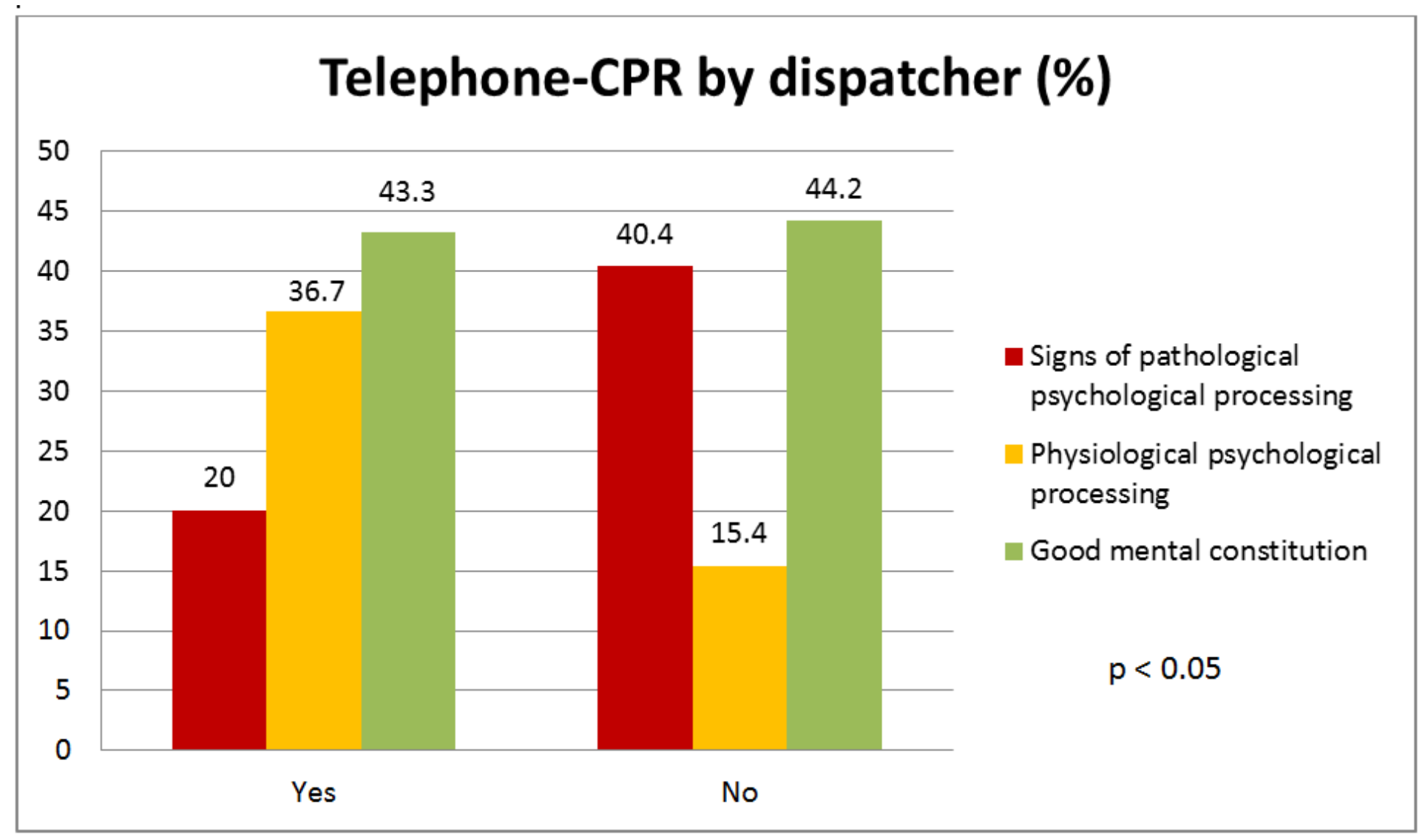

Figure 2

Probability of different psychological processing of the bystander in cases with and without dispatcherinstructed CPR in percentage. Signs of pathological psychological processing were significantly less in cases of telephone-CPR. 


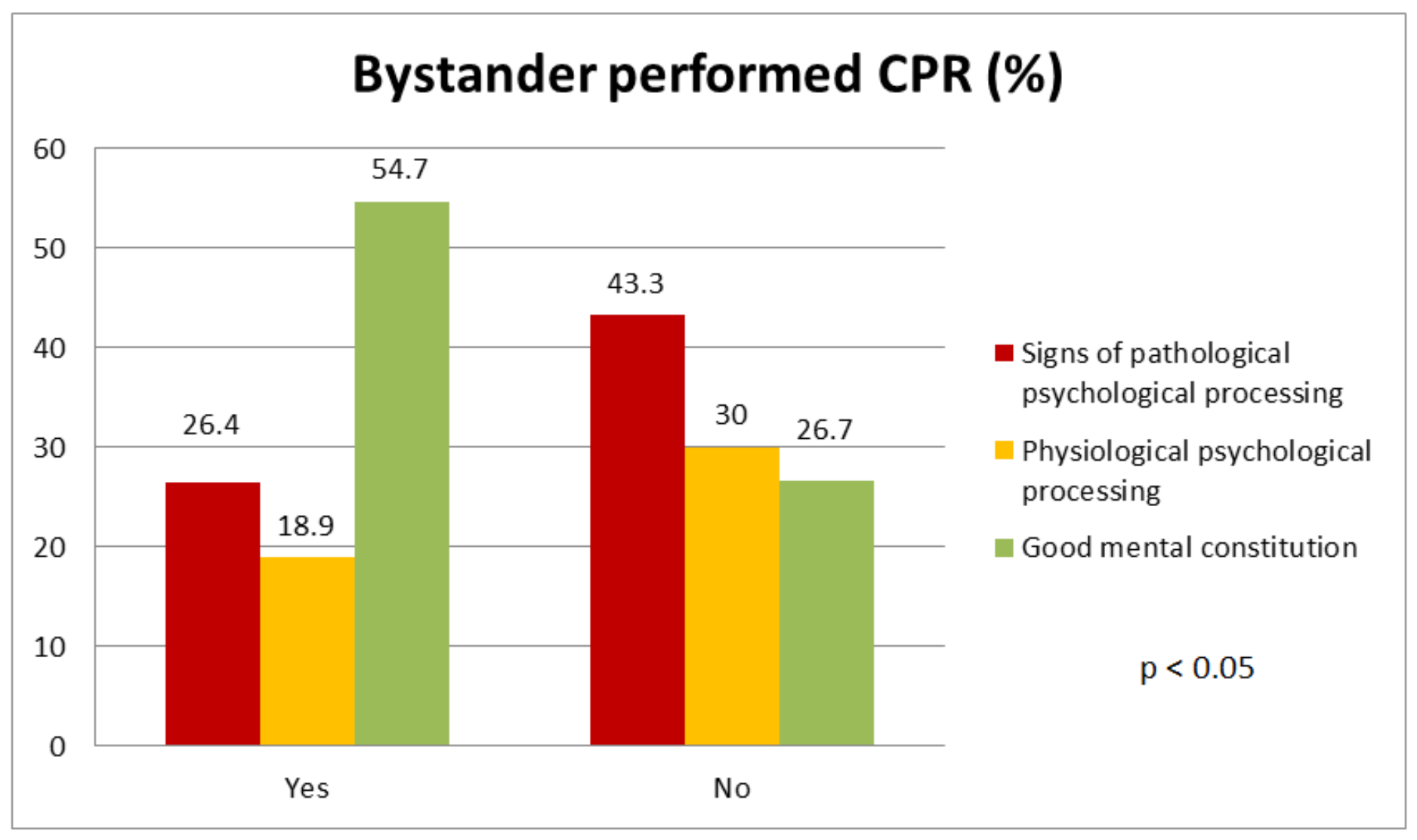

\section{Figure 3}

Probability of different psychological processing of the bystander in the group of bystanders performing CPR or not. A good mental constitution is significantly more often, in cases, where the bystander performed CPR.

\section{Supplementary Files}

This is a list of supplementary files associated with this preprint. Click to download.

- Additionalfile1.docx 